Review

\title{
Five Approaches to Social Sustainability and an Integrated Way Forward
}

\author{
Robert H. W. Boyer ${ }^{1, *}$, Nicole D. Peterson ${ }^{2}$, Poonam Arora ${ }^{3}$ and Kevin Caldwell ${ }^{1}$ \\ 1 Department of Geography \& Earth Sciences, University of North Carolina at Charlotte, McEniry 324, \\ 9201 University City Blvd., Charlotte, NC 28223, USA; kcaldw19@uncc.edu \\ 2 Department of Anthropology, University of North Carolina at Charlotte, Barnard 217, \\ 9201 University City Blvd., Charlotte, NC 28223, USA; npeterson@uncc.edu \\ 3 Department of Management and Marketing, School of Business, Manhattan College, 518 De LaSalle, \\ 4513 Manhattan College Parkway, Riverdale, NY 10471, USA; poonam.arora@manhattan.edu \\ * Correspondence: rboyer1@uncc.edu; Tel.: +1-704-687-5979
}

Academic Editor: Marc A. Rosen

Received: 29 June 2016; Accepted: 25 August 2016; Published: 6 September 2016

\begin{abstract}
Sustainability is often conceived of as an attempt to balance competing economic, environmental and social priorities. Over the course of three decades of scholarship, however, the meaning and appropriate application of the 'social pillar' continues to inspire confusion. In this paper, we posit that the inherent challenge of understanding social sustainability is its many legitimate meanings plus a lack of interdisciplinary scholarship. We draw from literature in multiple disciplines to illustrate five different ways that the concept of social sustainability has been applied in scholarship and professional practice, and highlighting the importance of applications that acknowledge placed-based, process-oriented perspectives that understand social, economic, and environmental imperatives as integrated concepts. Ironically, this framing forecloses on social sustainability as an entity distinct from environmental and economic sustainability. We believe that organizing the conversation around these five applications can help advocates of sustainability use the concept of social sustainability in clear and powerful ways while avoiding applications that relegate the social dimensions of sustainability to an afterthought.
\end{abstract}

Keywords: social sustainability; three-pillar model; sustainable development; interdisciplinary

\section{Introduction}

Sustainability and its policy corollary, sustainable development, have inspired intense scholarly and public debate since their international coming-of-age in the 1987 Brundtland Commission Report [1,2]. Kidd [1] documents how the term 'sustainability' originated as an exclusively descriptive concept in agricultural sciences and ecology in the middle twentieth century. In the past thirty years, however, sustainability scholarship has diffused and diversified, now serving as the cornerstone of plans and policy documents at every geographical scale and sector. Consistent across contemporary interpretations and applications of sustainability is a focus upon-often, striking some balance among-economic, environmental, and social priorities. This simple three-pillar heuristic, referred to in different contexts as 'the three-legged stool,' 'the triple bottom line', the 3 E's (economy, ecology, equity), or the 3 P's (prosperity, planet, people), implies that solving some of the world's most complex dilemmas entails shifts in familiar concepts rather than uprooting and rebuilding society from scratch. Over time, as scholars of diverse fields have developed scores of methods for measuring and achieving sustainable development (see for example [3]), the social pillar has earned a reputation for elusiveness [4-8], and even chaos [9] in part because social priorities are diverse and context specific. The current opacity surrounding social sustainability, we argue, results from a multiplicity of legitimate 
meanings, lack of cross-disciplinary communication, and a reluctance to engage diverse and local sources of knowledge in scholarly research.

As such, this paper has two major objectives: (1) To synthesize existing literature relating to the 'social' dimension of sustainability with special attention to the practical role of the social pillar within the broader framework of sustainability; and (2) to advance an interdisciplinary conversation about the social roots and social remedies to twenty-first century crises like global climate change, the decline of global ecosystems, and transitions in energy production. Below, we offer a typology of social sustainability applications that vary by their degree of integration of the social, environmental, and economic pillars of sustainability. This extends previous work that has identified specific properties of social sustainability (e.g., $[4,5]$ ) by articulating a typology for how different scholars and practitioners integrate - or fail to integrate-different dimensions of sustainability. We also suggest that this typology offers an avenue for more critical development of the broad concept of sustainability. Our analysis here indicates that a more integrated understanding of the economic, environmental, and social pillars of sustainability requires a framework that acknowledges the legitimacy of local knowledge and the importance of decision-making processes in policy making and business.

Our objective is neither to pinpoint a single or ideal meaning of social sustainability, nor to conduct a comprehensive review of the literature. Rather we draw from literature in urban planning, geography, anthropology, and business management to articulate the strengths and weakness of using the social dimension of sustainability in different ways. We suggest that current ideas about the social pillar attribute to it one of the following roles, each with specific limitations and consequences:

(1) A stand-alone objective or 'third pillar';

(2) A constraint upon economic and environmental imperatives;

(3) A precondition for thriving economic and environmental systems or 'social capital';

(4) A causal mechanism of environmental and economic change; and

(5) A fully integrated, locally-rooted, and process-oriented approach to sustainability.

The sections that follow detail these different applications, reflecting on when they make sense to use in theory and in practice. We believe that organizing the conversation around these five applications can help advocates of sustainability use the concept of social sustainability in clear and powerful ways while avoiding applications that relegate the social dimension of sustainability to an afterthought. To arrive at our conclusion about the importance of an integrated, place-based and process-oriented approach to sustainability, we draw on a wide range of studies and examples from the disciplines of urban planning, geography, anthropology, and business management literature. The following section reviews existing literature on the challenges of applying the social dimension of sustainability, and Section 3 discusses methodology before descending into the five approaches for applying social sustainability.

\section{Why Is Social Sustainability on the Margins of Sustainability Scholarship?}

In the introduction to a special issue on "the missing pillar" of social sustainability in the journal Sustainability: Science, Practice, and Policy, Magnus Boström [4] contemplates why the social pillar of sustainability is more challenging to "analyze, comprehend, define, and incorporate into sustainability projects" than its associate economic and environmental pillars. Firstly, explains Boström, social issues are the consequence of competing interests and values, uncertain causes and effects, and their implications on many areas of life. Analytical methods in the social sciences struggle to describe these complexities, and large-scale data collection often fails to capture the intricacies of lived experience. This complex reality frustrates attempts at objectively describing social phenomena, as scholars have suggested for decades [10].

Second, the social pillar remains marginalized by a sustainability agenda that is historically rooted in specific forms of environmentalism based in models of global capitalism that thrive upon the exploitation of natural and human capital. The division of the economy, the environment, and "society" 
into three distinct elements is a matter of expediency with important, but often overlooked political implications. For example, common social justice issues such as crumbling neighborhood infrastructure and poor access to open space and fresh food are environmental issues from the perspective of residents living in corroding and toxic neighborhoods, but these issues have traditionally been overlooked by a sustainability agenda that tends to focus on 'green' issues of ecosystem conservation rather than 'brown' issues of urban inequality [11]. What counts as economic or environmental issues, in other words, depends on scale, perspective, norms of interaction, and politics [12,13], so categorizing issues into the three pillars is an inherently political act. Relegating social aspects of sustainability to miscellanea or as a less important element of sustainability neglects the deeply social nature of economies (as social tools of exchange, e.g., [14]) and the ways that environments are also unavoidably understood and acted upon through cultural ideas and social relationships $[15,16]$.

As such, social sustainability has been addressed by diverse scholars in diverse ways, including some applications that place social issues at the very center of sustainability discussions. Distinguishing among these different interpretations may help practitioners of sustainability more readily recognize the implications of how they frame social sustainability and sustainability more broadly. Beginning with applications that frame social sustainability as a stand-alone priority alongside environmental and economic priorities, we detail the different roles that the social pillar has played and continues to play in different scholarly and practical contexts. Our analysis progresses through frameworks that offer increasingly active and centralized roles for the social pillar, until we arrive at a fully integrated, process-oriented, and locally-rooted conception of sustainability that forecloses on the idea of the idea of social sustainability as a distinct category. Building on these applications, we contend that sustainability is best understood through research and efforts that are socially framed, grounded in local experiences and concerns, and integrated across disciplines and professions.

\section{Methodology}

This paper emerges from conversations among members of the Integrated Network for Social Sustainability (INSS), a research coordination network (RCN) supported by the National Science Foundation. Since 2012, the INSS has worked to stimulate discussion and interdisciplinary scholarship around the often-overlooked social aspects of sustainability. Through conferences, research groups, and networking opportunities INSS members, including scholars and professionals from diverse sectors, are united by the urgency of global environmental crises and their potential inclusive, equitable, and human-centered solutions. This paper employs grounded theory methodology [17], working abductively to build robust analytical categories that make sense of social sustainability - a concept that has been inconsistently applied by scholars of diverse disciplines. We began by forming provisional categories, distinguished by differences in the way that authors frame the social dimension of sustainability relative to economic and environmental dimensions of sustainability. We then tested these provisional categories against new data-in this case, additional academic literature-to identify distinct ways that the social dimension sustainability inform the broader concept of sustainability. When literature failed to conform to existing categories, we formed new categories to accommodate variation. While we do not claim to have conducted a comprehensive review of literature in our various disciplines, we claim that the five categories below accommodate perspectives on social sustainability from multiple disciplines, and we offer these categories as guideposts to a conversation that can help scholars use the concept of social sustainability in productive and clear ways.

Our analysis suggests a rough typology that shows (1) increasing interest in integrating social, economic, and environmental priorities that have traditionally occupied distinct ontological spheres; and (2) growing concern with social sustainability as an inclusive, non-hierarchical governance process. Without claiming to exhaustively catalogue all applications of social sustainability, each section presents several examples of each typology as they apply in the public and private sector. 


\section{Five Approaches to Social Sustainability}

\subsection{Social Sustainability as a Distinct Objective}

The first, and perhaps most expedient application of social sustainability is as a stand-alone objective, separate from environmental and economic sustainability concerns. In this model, social sustainability can exist either alongside environmental and economic pillars or as a so-called 'one-pillar model' (see Figure 1) [18]. Most critically, however, the social pillar as a stand-alone objective does not constrain, propel or in any way interact with the other pillars. Such an application supports the idea of unique social sustainability indicators or a social sustainability index that carries meaning independent of the other pillars or the broader concept of sustainability. Bramley and Power [19], for example, test the effect of 'urban form' on 'social sustainability' by reducing the two concepts to measurable criteria and testing their association statistically. The authors choose residential density as a proxy for urban form, and survey for undesirable neighborhood indicators like dissatisfaction with the neighborhood; the presence of neighborhood problems like crime, vandalism, traffic, and noise; and difficulty of access to of certain neighborhood amenities. Controlling for multiple contextual variables, the authors show that residential density increases neighborhood dissatisfaction and other neighborhood problems, but increases access to certain neighborhood amenities.

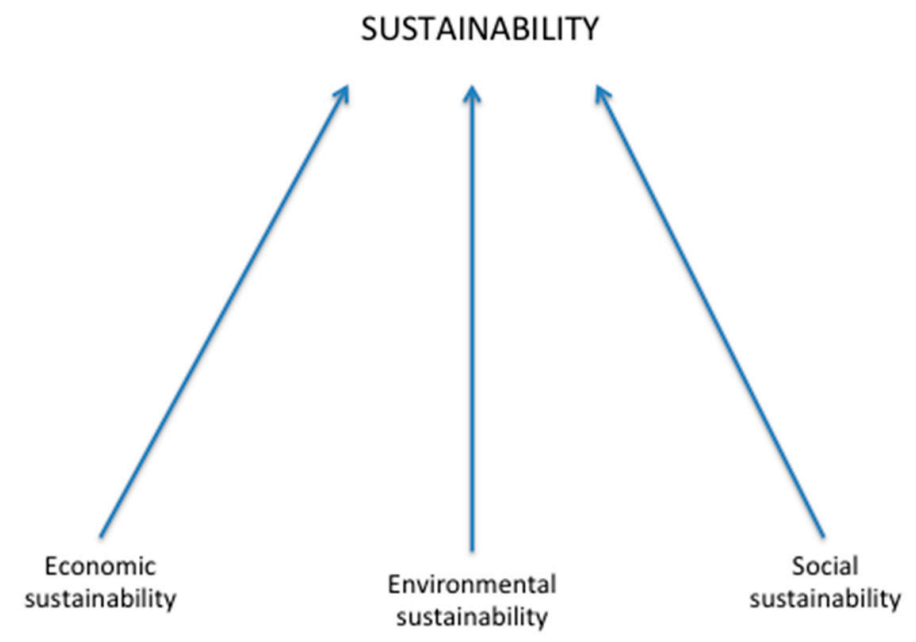

Figure 1. Social sustainability as a stand-alone pillar.

Such an application extracts social sustainability from the other pillars of sustainability and from a conception of sustainability as integrating multiple priorities. This isolation denudes social sustainability of its transformative potential by effectively equating social sustainability with social issues.

Applying social sustainability as if it were an isolated value may be most useful in comparing diverse applications of sustainability, in diverse contexts, at a single point in time. For example, Saha and Paterson [20] explore the potential for sustainable development in USA municipal governments. Reasoning that achieving sustainable development requires some balance of the 3E's (economy, environment, and equity), the authors select 14 environmental, 11 economic, and 10 equity-oriented programs, and propose that jurisdictions with a more balanced policy portfolio are more likely to progress toward sustainable development. Social equity programs include neighborhood planning, anti-gang programs, affordable housing provisions, homeless prevention programs, etc. While the study is able to compare hundreds of local jurisdictions at once, this relatively broad analysis takes for granted that diverse public programs interact or somehow yield more balanced outcomes on-the-ground, despite traditional institutional barriers between social and environmental programs [4]. 
Most critically, evaluating social sustainability as a stand-alone objective reinforces a narrative that the three pillars of sustainability harbor meaning independent of one another. Other studies indicate that, at the very least, we need to understand how different pillars interact in order to characterize and assess sustainability. Littig and Greissler [18] criticize the rise of so-called 'one-pillar' models of sustainability, created primarily to optimize one dimension of sustainability while paying only cursory attention to the others. The authors offer ecological footprinting i.e., [21] as an example of a model focused primarily on ecological systems with a limited focus on social or economic issues. Very often, discussions of sustainable development prioritize sustaining economic growth and profit in the face of environmental and social disruption [22], while the disintegration of social systems rarely evokes calls for sustainability.

So long as the social pillar remains an addendum to economic imperatives, the pillar's meaning will shift with the obstacles and opportunities that economic imperatives face. In other words, the detailed meaning of social sustainability is irrelevant within stand-alone applications so long as its chief purpose is to facilitate conditions for economic growth. This is apparent among traditional for-profit organizations where the practice of accounting has long been thought of as the "language of business" because it provides an effective and efficient method for businesses to "keep score"; it is a "technical language", honed to its specific (economic) purpose" [23]. The language emphasizes that all business activities end in a balanced annual report focused on shareholders and economic wealth creation. Despite sections in reports about employee engagement, social and community links, and corporate social responsibility, the principle objective of the report is to distinguish costs from revenues. Thus, the social aspects of business (e.g., investment in employee well-being and training, connections with or investment in local communities, charitable contributions and other corporate social responsibility activities) continue to register as expenses, separate from the economic purpose of the business. They are effectively an isolated objective to be realized as-and-when convenient, and thus frequently limited to symbolism [24]. Here the economic prowess of an organization defines its commitment to and investment in the social aspects, essentially reducing the social pillar to that which is plausible while in pursuit of a primarily economic agenda.

\subsection{Social Sustainability as a Constraint upon Economic and Environmental Imperatives}

Social sustainability can also be envisioned as a constraint upon economic and environmental imperatives (see Figure 2). Scott Campbell's [25] oft-referenced "planner's dilemma" imagines sustainable development as a process of reconciling competing social equity, economic development, and environmental protection priorities. Professional urban planners, explains Campbell, struggle with tensions between these priorities constantly, and sustainable development seeks resolutions to their inherent contradictions in day-to-day practice. The 'social' vertex of the planner's triangle only makes sense in the context of a "property conflict" (the struggle to balance priorities of private wealth accumulation and the fair distribution of that wealth) and a "development conflict" (the struggle to conserve environmental resources without disproportionate penalty to any particular group). As such, the social vertex of the planner's triangle is asymptotic: it can be approached, but can only be expressed relative to economic and environmental priorities.

Amekudzi, Khisty and Khayesi [26] and Amekudzi, Khayesi, and Khisty [27] apply the three pillars as constraints upon one another in their three-dimensional "sustainability footprint" metric. Sustainability Footprint measures the rate of change in some quality of life indicator as a function of environmental and resource consumption indicators. In their 2009 comparison of highway expansion projects in two major USA regions, the authors measure percent change in congested travel time (a quality of life indicator) as a function of changes in greenhouse gas emissions and fuel consumption. In their 2015 study, the authors examine national-scale changes in the non-income Human Development Index as a function of change in ecological footprint and change in gross national income per capita. 


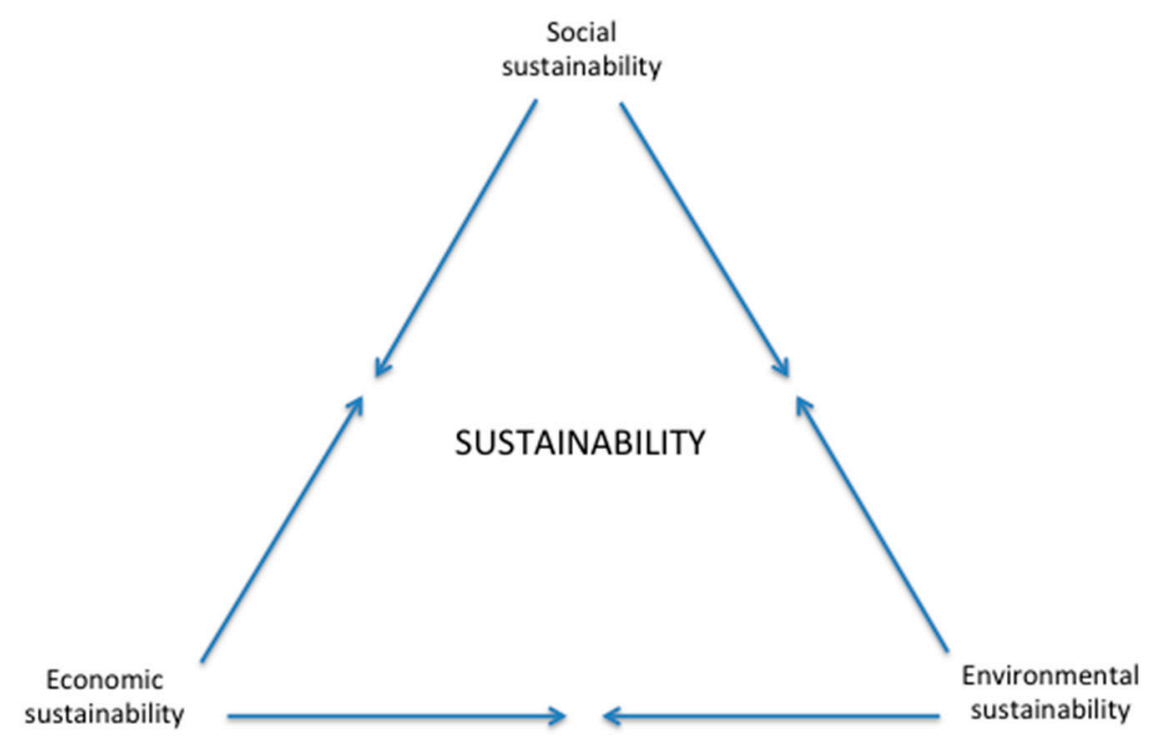

Figure 2. Social sustainability as a constraint on other sustainability pillars.

In this application, the 'social' metric represents some socially desirable outcome, rather than claiming to represent all social (non-economic, non-environmental) values of society. The challenge, as the authors acknowledge, is collecting consistent and meaningful data across contexts. Nevertheless, such an approach frames sustainability as a three-dimensional concept, with a central role for social variables.

Social sustainability as a constraint on the other pillars of sustainability is also apparent in non-profit and business applications. Beginning in the 1990s, CERES, a Boston (USA)-based non-profit, led the Global Reporting Initiative (GRI) to help corporations focus on their net impact on all stakeholders, and by extension all of society. This initiated a dialogue on the interactions and linkages between the three elements of the triple bottom line. A timely and positive example is a decision by TJX Companies to keep their TJ Maxx (TJM) stores closed on Thanksgiving Day, 2015. An ever-growing number of retailers (such as Wal-Mart, Best Buy, JC Penny, and Kohl's) opened their doors on Thanksgiving Day as an early start on Black Friday shopping-the single largest shopping day for retailers in the US-requiring employees to work on what is considered a family-oriented holiday. TJM emphasized, in a new advertising campaign, that their stores would be closed on Thanksgiving Day so as to allow both their employees and customers social and family time, an essential aspect of social well being. Integrating the social dimension in the overall brand image is an important first step by organizations towards giving equal weighting to all three pillars. As pointed out by Milne and Gray [28] however, the inclusion of all three pillars has to go beyond the acceptance that the social aspect enhances both economic potential by generating goodwill among customers, and environmental credibility due to the reported positive activities. Though these activities create resilience, they do not necessarily ensure that social sustainability is fully integrated into the decision process [29].

In the case of natural resource management in Loreto, Baja California Sur, Mexico, we can see the movement from a one-pillar model to one with more integration. As documented in research by Peterson [30,31] the staff members of the Loreto Bay National Park initially struggled to enforce Mexican laws in the marine protected area, including rules about equipment and endangered species. Early on, discussions about the development of the management plan for the area emphasized the environmental and economic value of the marine area, focusing on the problem of overfishing by commercial fishermen. Solutions for overfishing included education and restriction as ways to redirect what were seen as economic efforts of fishermen away from environmental damage. However, as the protected area staff entered into discussions with the fishermen, they developed a more complete understanding of fishermen motives and values, and began to work on developing economic 
development projects with the fishing communities. In essence, the staff's vision of sustainability shifted to include social aspects of fishing communities in planning and efforts, and understanding the influence of social values and relationships on fisheries and the protected area.

This social-pillar-as-constraint framing often prescribes pragmatic tinkering-alleging that 'sustainable' solutions will emerge in practice as public and private decision makers discover solutions that achieve multiple criteria at the same time (see for example [2,31]). A manifestation of this second pillar is typified by the establishment of a unit or office for corporate social responsibility, or CSR, with the stated goal of considering the well being of individuals and groups impacted by the corporation's economic or environmental activity. While the establishment of CSR could be framed as social issues stimulating improvements in environmental or economic pursuits (more akin to the fourth application discussed below), in practice addressing social issues through CSR programs more often serves as a constraint or condition upon existing profitable activities. Milne and Gray [28], for example, found that reporting on CSR activities is frequently limited to supportive news stories, a lack of discourse on major social problems, and oversight of issues like ecological footprints and social justice. Similarly, Sridhar [32] finds that companies often fail to report the social variables on which they fall short. Thus, though CSR is established to stimulate activity around social sustainability, pursuit of social programs is intended to support the overall economic performance of the corporation, thereby responding economic stimuli rather than transforming or stimulating them. Establishment of a third pillar brings social sustainability into the boardroom and strategic conversations in businesses by effectively linking the bottom line to the three Ps.

\subsection{Social Sustainability as a Pre-Condition for Environmental and Economic Sustainability}

Building on the idea that the social, environmental, and economic pillars interact, another application understands social sustainability as a social capital stock that acts as a pre-condition for economic and environmental health, and may even compensate for shortcomings in economic or ecological (i.e., "natural") capital (see Figure 3). Definitions of social capital abound, but we draw from Putnam and colleagues' [33] oft-cited definition of social capital as, “... features of social organization such as networks, norms and trust that facilitate co-ordination and co-operation for mutual benefit" ([33], p. 35). Multiple authors cite social capital as an important, if still insufficient, property of social sustainability $[6,9,12]$.

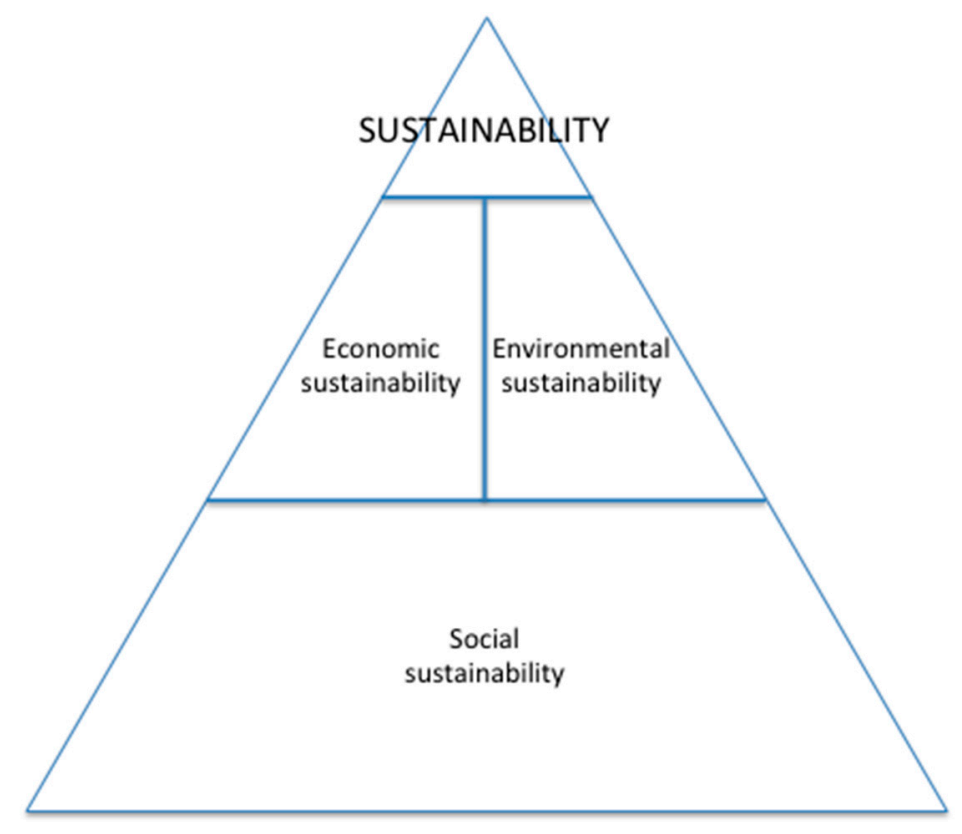

Figure 3. Social sustainability as a foundation for other priorities of sustainability. 
Dancing Rabbit Ecovillage (www.dancingrabbit.org), an intentional community in rural northeast Missouri, USA, models how an unconventional investment in communication and conflict resolution skills allows for a lifestyle of abundance amidst strong self-imposed limitations to resource consumption. Dancing Rabbit was founded in 1997 by a group of recent college graduates from the San Francisco Bay Area of California (USA) hoping to form an experimental "eco-town". The small founding group settled on an unregulated rural parcel, where the community has blossomed to over 60 residents, including individuals of various age and geographic origin. Most residents of Dancing Rabbit earn annual incomes below the federal poverty line through a mix of on-site and internet-based employment, but while incomes are low by US standards, few in the community consider themselves impoverished. Indeed, members of Dancing Rabbit thrive at a fraction of the economic or environmental cost of mainstream American households. By the community's own calculations, members of Dancing Rabbit consume less than $10 \%$ the electricity, water, propane (for cooking), and motor fuel than the average American. This is accomplished through context-sensitive building design, simple off-the-shelf technologies, and a patchwork of cooperatively owned facilities. For example, the sixty-plus residents share four vehicles (one pickup truck and three sedans) in a region with zero public transit options and very few destinations within cycling distance. The four cars-powered either by on-site solar photovoltaic panels or by biodiesel-are owned, maintained, and insured by the Dancing Rabbit Vehicle Cooperative (DRVC). Weekly DRVC meetings help coordinate use of the vehicles, which residents minimize by ride-sharing, errand-sharing, and fulfilling as many needs as possible on-site. Co-op members pay a flat rate per mile they drive. The success of this system involves constant information exchange among members-the social "cost" of owning a fleet of vehicles cooperatively-but they do have access to a reliable transportation system at a fraction of the monetary cost of owning and insuring a personal automobile. Other cooperatives at Dancing Rabbit include Better Energy for Dancing Rabbit (BEDR), a solar electricity cooperative; Cattail Commons, which provides internet access, bathing facilities, and access to common dining and meeting spaces; a humanure cooperative, which coordinates the collection, composting, and reintegration of human excrement into the soil; and multiple food cooperatives which coordinate gardening, cooking, and meals.

This mosaic of cooperatives meets the daily needs of residents at "one-planet" levels of resource consumption, but requires its members to make a unique investment in social competencies. Residents invest hours of each day practicing non-violent communication skills, meeting facilitation skills, and resolving interpersonal conflict that accompany collective ownership of resources [34]. As such, social capital built up intentionally by members of the community, allows households at Dancing Rabbit to survive and thrive without the financial capital that most individual household require to access very basic needs in the mainstream.

Inversely, we see how the disintegration of social ties leads to environmental decline. Lansing's [35] work shows how a Balinese temple system allowed for the complex coordination of irrigation, pest control, and social relationships, minimizing conflict between water users and increasing agricultural efficiency. However, this system was disrupted under colonial rule, and the environmental, economic, and social benefits were lost. Urban ethnographic work by Anderson [36], Klinenberg [37], and others illustrate a cyclical pattern of violent crime, damage to neighborly social ties, and environmental neglect. A similar set of examples highlights the role of social relationships in marine resource management, wherein local norms and rules of use allow for sustainable management systems [38]. The growth of these and similar studies highlight the value of social networks and interpersonal relationships for environmental sustainability.

There is preliminary evidence from interviews conducted with agribusinesses in the Argentine Pampas, one of the most fertile areas in the world, that at least some of the focus on the economic or profit pillar may in turn be motivated by underlying concerns of social sustainability. Arora and colleagues [39] find that longer-term links with the community are typically manifested through land ownership. Decision-makers are not only more likely to invest in social capital and the creation of 
learning-based organizations if they own the underlying land, but are also more likely to make a greater commitment to finding solutions to social and communal concerns, even at the cost of direct economic benefits. Thus, in this case, the investment in social capital motivates problem solving that is holistic and inclusive of economic and environmental concerns.

\subsection{Social Sustainability as the Casual Mechanism of Economic and Environmental Change}

The prior applications suggest that communities can improve or protect their economy and physical environment through investments in social wellbeing. Our fourth application (Figure 4) of social sustainability suggests that social sustainability can be understood as the stimulus for, rather than just a precondition of, environmental and economic change. A more integrated view of sustainability suggests that environmental problems are ultimately social—not technological—problems, and that technological change is inextricable from social change.

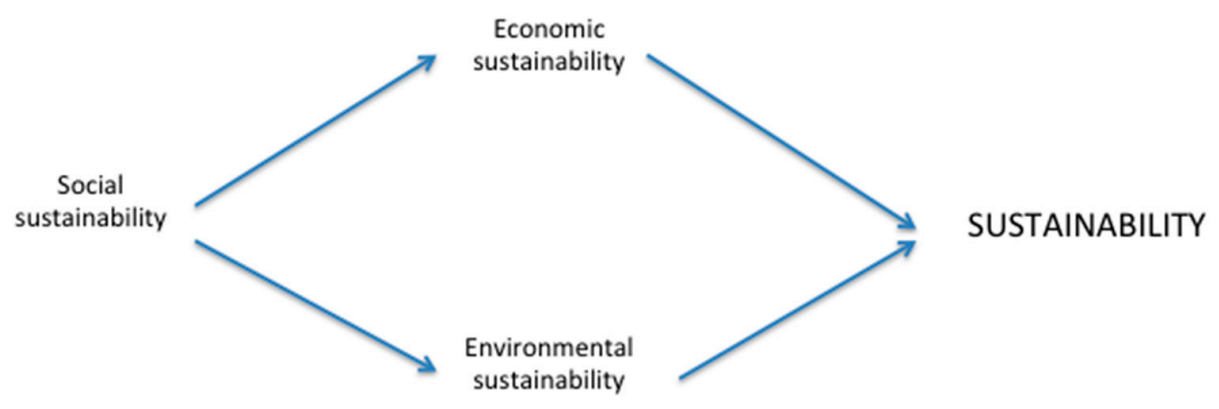

Figure 4. Social sustainability as the causal mechanism for change in other sustainability pillars.

In the past twenty years, scholarship on socio-technical transitions has applied knowledge of historical shifts in technological systems [40], to better understand and thus stimulate the dramatic socio-economic transformations necessary to avoid global environmental catastrophe. This realm of scholarship has demonstrated that radical new systems of production are unlikely to emerge fortuitously from the marketplace because of socio-technical regimes that are "locked-in" by mutually reinforcing social and technological structures. The dominance of petroleum-powered automobiles, for example, is reinforced by a global network of complementary structures (e.g., refueling stations, repair businesses, parts suppliers, engineering curricula) that exist beyond the physical technology of combustion engines [41]. Radical alternatives to dominant technologies, however, may emerge from isolated market "niches" where innovation and experimentation takes precedent to well-established economies of scale. In niches, networks of actors experiment with sub-optimal, yet potentially more sustainable, material practices. With roots in evolutionary economics e.g., [41-43], early socio-technical transitions scholarship imagined radical new social and technological configurations (e.g., electric cars) emerging from "strategic niches" - effectively laboratory settings protected by government subsidies or corporate sponsorship. Strategic niches provide an opportunity for stakeholders within complex systems of production and consumption to support the development of alternative products outside the selection pressure of incumbent regimes [44]. Alternative regime structures emerge within "niche" networks of individuals willing - either because of ideology or perceived economic reward-to assume the risks of experimentation with alternative-and presumably environmentally sustainable - practices that, eventually, have the potential to acquire a larger market presence.

More recently a wave of "grassroots innovation" scholarship has looked to niche networks motivated more by political ideology and community need than by profit per se [45]. Boyer [46], for example, illustrates how Los Angeles Eco-village (Los Angeles, CA, USA) formed to address interracial tensions in the Koreatown neighborhood after the 1992 Los Angeles riots, and has since spurred multiple neighborhood scale infrastructure projects to mitigate flooding, reduce automobile congestion, and improve local air quality. Similarly, Smith [47] traces the development of wind-powered 
electricity in Denmark to local activist networks willing to experiment with wind turbines on their own property.

Environmental progress, from this perspective, is stimulated by social changes such as alternative modes of thinking, interacting, or governing. Recent work in behavioral economics and related disciplines has capitalized on this insight to highlight the social influences on decisions about environment and other topics, including how behavior can be changed through subtle nudges, changing defaults, and framing issues in slightly different ways [48-51]. For example, residential water use decreases by simply telling residents that their neighbors conserve water [52]. Many companies and organizations now incorporate these strategies into their efforts, and President Barack Obama recently created a Social and Behavioral Science Team to integrate this work into US government programs.

In addition, some researchers working within this paradigm view social issues at the root of environmental and economic issues, and thus addressing environmental and economic issues requires an initial focus on social issues, relationships, and institutions. For example, advocates for environmental justice in the United States find that certain communities experience more environmental risks due to a legacy of discriminatory land use policies like redlining and the misallocation of public infrastructure [53-57]. In many cases, these policies lead to the accumulation of vulnerabilities to risk, both in terms of spatial proximity and in terms of the ability to respond to risk through adaptation or recovery of health [58-60].

In these and other cases, viewing environmental and economic change as stimulated by social change can lead to a broadened portfolio of potential policy interventions. Scholars of social practice theory, for example, have begun to address issues of unsustainable consumption by focusing on the mundane practices that individuals perform unconsciously, from day to day. Shove, Pantzar, and Watson [61] conceive of social practices as the materials, meanings, and competencies that individuals combine and recombine in the performance of daily tasks. Thus, unsustainable energy systems extend far beyond energy production (e.g., power plants) and into daily activities like cooking, bathing, commuting, and watching television that integrate energy as one material element [62]. Understanding energy as one element in a diffuse array of practices presents new opportunities for policy intervention. For example, Shove, Pantzar, and Watson [62] discuss how a Japanese initiative to reduce indoor energy consumption began by changing meanings of appropriate work attire that promoted lighter clothing (and less need for air conditioning) in the summer and heavier clothing (and less need for indoor heating) in the winter. As such, a change in social practice contributed to changes in energy consumption, which is traditionally an 'environmental' variable.

Understanding social sustainability as a driver of the two other dimensions emphasizes the importance of social relationships and culture for the way our society is organized, both now and in the future, and suggests potential future directions for sustainability that involve alternative visions of relationships among these elements, yet this application of social sustainability still images 'economic' and 'environmental' priorities as somehow separate from social variables. In the final section, we suggest that a growing interest in local governance creates the conditions for a re-envisioning of sustainability that is local, dynamic, and striving toward full integration.

\subsection{Social Sustainability as Place-Centered, Process-Oriented Sustainability}

Whereas the first four applications of social sustainability imagine how social phenomena constrain, shore-up, or propel environmental and economic dimensions of sustainability, the fifth understands social, economic, and environmental imperatives as overlapping in local experience. As discussed in earlier sections of this paper, 'economic' issues to one constituency can register as 'social' or 'environmental' issues to others. As such, relegating any particular issue to an exclusive pillar can overlook how diverse individuals in diverse places experience these dilemmas differently. At a human scale, then, sustainability becomes an exercise in embracing and reconciling plurality, which we argue is a matter of better democratic governance. 
The fifth application of social sustainability imagines sustainability as the integration of values and entities that have been historically separated into different disciplines, like economics, history, and ecology. Modernist social science relies upon and reinforces clear conceptual boundaries between humanity and nature, capital and labor, subject and object, masculine and feminine, urban and rural, et cetera [63]. These dualisms foreclose on our ability to observe ontological overlaps (i.e., the possibility that humanity and nature constitute one another), but also implicitly encourage conceptual hierarchies such that, for example, humanity is distinct from- and morally superior to nature; and the masculine is distinct from- and morally superior to the feminine [64]. The fifth application of social sustainability suggests that the three-pillar model serves to reinforce disciplinary divisions, leading to a similar set of judgments about their relative worth. This can be seen in discussions about trade-offs among social, economic, and environmental goals [65] or in the general neglect of social sustainability discussed in previous sections of this article.

While the prior four sections illustrate different ways that the three pillars of sustainability can constrain and propel one another, the fifth application attempts to transition toward an integrated view of sustainability that understands economic, environmental, and social concerns as intersecting in the practices and perspectives of individuals. This perspective is thus counter-intuitive as it forecloses on the existence of a separate 'social' sustainability, and encourages us to consider that the environment and the economy are abstract categories that exclude perspectives rooted in specific places and experiences, constrain how we think about and enact sustainability.

This approach aligns with scholarship that is critical of sustainable development as envisioned by international development agencies [22,66,67]. Observing the injustices and limits of a one-size-fits-all development strategy, these authors look toward local knowledge and grassroots movements as a guide for policy and action. In the same way, sustainability can be understood as locally rooted in ideas, motives, and activities. One approach is to see sustainability as the outcome of everyday pragmatic problem solving, or "actual existing sustainabilities" [68]. This idea undermines the dominance of one-size-fits-all perspectives in sustainability pursuits and highlights the need to recognize diverse visions for and perspectives about local environments [69-75]. Rice and colleagues [76] echo the conclusions of many of these authors when they remind academics that their failure to fully incorporate non-academic perspectives in their research perpetuates the dominant technocratic discourse of sustainability, and limits our willingness to experiment with new ideas or possibilities.

There have been a variety of efforts to invite marginalized voices into decisions, including participatory planning processes and civic engagement. Research on these initiatives document the challenges of including local perspectives through real-as opposed to token-engagement, as well as other barriers ranging from logistical challenges to differing forms of presentation to the variety of goals and motivations that enter participatory processes [77-80]. "Engagement practices are not merely techniques to be acquired in order to organize meetings effectively, but highly consequential choices that shape the inherently political process of planning and policy making [81,82]" in ([83], p. 273).

Decolonization approaches draw on work in intersectional and feminist studies to show how long-established institutions and practices can marginalize divergent perspectives, perpetuating processes of colonization that privilege certain voices and points of view ([84], p. 95). For sustainability efforts, diverse perspectives can introduce new ideas and relationships to address technological and social challenges that are rooted in a history of European capitalist expansion. Arturo Escobar [85] analyzes the visions, strategies, and activities of Afro-Colombian activists in Colombia's Pacific rainforest region, including their efforts toward land and political autonomy in interaction with government and transnational organizations that have different visions of the environment, lands, and culture of the region. Through this work, Escobar and his interlocutors propose a new way to understand environment, globalization, and conflict beyond those offered by Eurocentric paradigms. The idea of envionmentalisms recognizes the variety of forms that environmentalism can take; in the Afro-Colombian case, environmentalism is also about territory, lifeways, justice, and autonomy. 
This approach would posit that "one-pillar" approaches to sustainability fail to acknowledge complexity and multifaceted problems represented by the convergence of a large number of competing needs. This is what Leonie Sandercock [86] refers to as the challenge of planning the "cosmopolis", which is a "construction site of the mind, a city/region in which there is genuine connection with, and respect and space for, the cultural Other, and the possibility of working together on matters of common destiny, a recognition of intertwined fates" ([86], p. 7). Sustainability is therefore the challenge of plurality and is thus inherently political, requiring "a democratically organized process of socio-environmental (re)construction" ([13], p. 38).

Place-based and process-oriented sustainability efforts use innovative governance approaches to bring together multiple perspectives, and to encourage local ownership of ideas and processes. A recent special issue in the journal Sustainability: Society, Policy, and Practice highlights that sustainability efforts are dependent upon relationships, education, and engagement [87]. One article [88] uses a series of examples to show that engagement and sustainability require addressing inequities of access to resources like clean water, knowledge, and political processes that act on both individuals and groups. Trust and collective governance are themes throughout the special issue that encourage sustainability to thrive in places like Peru, Argentina, and classrooms in the State of Michigan. For these cases, sustainability derives from accessible and inclusive processes. However, how these concerns are defined and negotiated vary with local perspectives and governance structures designed to engage concerns and barriers [89-93]. An integrated perspective on sustainability is thus implicated in more effective governance, which in turn relies upon attention to local contexts and ideas, assurance of access to necessary resources, and engagement of citizens in decision-making.

For example, Paul Fragua-a specialist in tribal community development-has worked with several colleagues to develop a guide for indigenous community self-assessment that moves communities beyond discussions of economic development to a perspective that includes culture, identity, history, and other key elements of community lives [94]. Working with a group of tribal experts to develop the assessment tool, the goal is to engage communities in dialogue-the outcome the discussion itself plus increased awareness of community needs. The assessment and community engagement process fosters local commitment and belief in the legitimacy of the community's needs, and the belief that each member has value. It promotes community dialogue, involvement and buy in, and does so through a perspective on sustainability that engages with local, context-focused governance processes.

We attempt to diagram this fifth application (Figure 5) of social sustainability by showing how social, economic, and environmental priorities intersect at the level of the individual. Each triangle represents an individual, and triangles intersect (i.e., engage in political dialogue) with one another. Triangles can be understood as what Escobar ([85], p. 6) labels, "historical subjects of particular cultures, economics, and ecologies; particular knowledge producers; individuals and collectives engaged in the play of living in landscapes and with each other in distinctive ways" (p. 6). Sustainability, then, is a process of dialogue and negotiation among these diverse individuals with distinct social, economic, and environmental interests rather than the reconciliation abstract 'social' interests with abstract 'environmental' and 'economic' interests. The practical challenge of this application is collecting and reporting data about sustainability in a consistent, systematic way. The application's disadvantages are effectively the inverse of the advantages of application \#1. Sustainability as an integrated, process-oriented, and place-based concept shares the challenges of solving so-called "wicked problems" [10]: problems that are unprecedented and context-specific, with oppositional problem framings, and solutions that cannot be tested at low-cost. As Rittel and Webber explain, such problems cannot be "solved" in a traditional or scientific (i.e., the traditional scientific method) sense because they are the consequence of diverse and sometimes oppositional perspectives about the nature of the problem. Coping with such challenges and building expertise in emerging fields of knowledge requires new forums for dialogue, and a willingness to reexamine to role of science in policy making (see also [2]). 


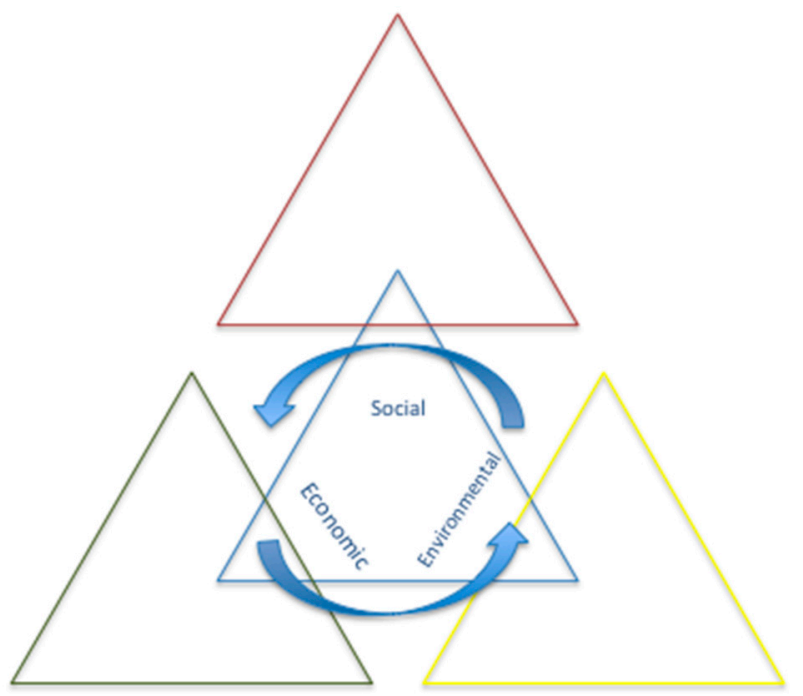

Figure 5. Social sustainability as place-based, process-oriented, and fully integrated. The different triangles represent different agents with unique perspectives that must, nonetheless, negotiate with the perspectives of other agents. Social, economic, and environmental priorities intersect in the experience of individuals.

\section{Conclusions}

This paper has shown that sustainability, particularly when social sustainability is of concern, can vary widely from application to application, but that we need both a grounding in local experiences and also a more systemic, integrated view of sustainability rather than separate economic, environmental, and social pillars. We anticipate that the "five applications" of social sustainability will challenge scholars and practitioners to consider more carefully how they invoke social sustainability, and perhaps question the wisdom of parceling sustainability into three priorities that are all ultimately political constructions.

In creating a typology of approaches to social sustainability, we have highlighted both diverse understandings of the concept but also the route(s) towards incorporating local experiences and governance into sustainability. As we have seen, incorporating context and governance allow for a sustainability system of local products and markets, and also increase both the relevance for local actors and ensure that sustainability efforts consider local contexts, needs, and desires.

Our typology thus shows the value of an integrated vision of sustainability that does not exclude certain experiences or domains from what is ultimately a holistic and systemic concern. As a stand-alone concept (Application \#1) social sustainability exists in isolation from two associate pillars, effectively stripping it of the ability to transform environmental or economic outcomes. Yet the content of any particular pillar-e.g., what counts as "environmental"—varies across places and diverse individuals. Other approaches (e.g., Applications 2, 3, and 4), encourage us to consider that social conditions constrain, pre-exist, or even simulate environmental and economic change. The fifth, fully-integrated application pushes this relationship farther to claim that these are not distinct spheres of action, but overlap and complement one another in complex and context-specific ways. In other words, to be a useful concept, sustainability must be understood as permeating almost all aspects of life and profoundly dependent on the specifics of local contexts. The implications for encouraging sustainability are significant, as it requires a different approach to sustainability from the previous applications, which tended towards essentially top-down or bottom-up efforts, rather than bringing these together.

Efforts that recognize how environmental, social, and economic values overlap in the experience people in specific places are able to achieve greater sustainability, as shown in examples throughout this paper. In many cases, these values have been essential to the culture of organizations like Native 
American groups [94], fishing communities [30,31], companies (e.g., TJ Maxx, Sydney, Australia), and other social groups (see $[35,36,40]$ ). Sustainability requires cultural change, which is inevitably holistic and local. In addition, culture change goes beyond individual ideas to encompass larger groups, even to national or global levels, implicating policies, institutions, and laws. The typology here suggests a way forward, as well as pioneering cases of success in creating more sustainable societies.

Our own efforts suggest ways to combine local context and values with engaged governance. As discussed above, this paper is rooted in discussions among members of the Integrated Network for Social Sustainability (INSS). The annual conference of the INSS has co-evolved with our changing understanding of social sustainability. In our initial years, annual conferences brought together hundreds of network members in one location in an attempt to unify multiple disciplines and sectors around a concise definition of social sustainability. In the past two years, however, we have experimented with a multi-site conference model in which members of different satellite locations convene online for several synchronous sessions while also administering local sessions in their respective locations. Conference locations in the past two years include Charlotte, North Carolina; Atlanta, Georgia; Chicago, Illinois; East Lansing, Michigan; Bend, Oregon; Washington, DC; Oxford, Mississippi; and London, UK. By effectively eliminating air travel, this conference model offers obvious economic and environmental benefits. More exciting, however, are new opportunities for local engagement that were impossible in a traditional single-site conference model. Facilitating simultaneous conferences in multiple locations allows network members to focus on particular local dilemmas alongside local advocacy groups that could not have participated in a conference hundreds or thousands of miles away. We have observed that a conference that is simultaneously global and local allows for more poignant trans-disciplinary lessons, a broader audience, and a lower carbon footprint.

In the short-term, a fully integrated, process-oriented, place-based sustainability privileges certain analytical methods over others. Case studies that draw from participant observation, participatory action research, and semi-structured interviews are arguably well suited to capture the peculiarities of place and to internalize the details that large-sample analytical methods overlook. This places demands upon scholarly networks to conduct qualitative work in compatible, if not yet standardized, ways so that results across contexts can be easily compared. It challenges academic disciplines that congregate around isolated journals and isolated conferences to branch out to new, interdisciplinary forums that invite assorted methodologies and novel perspectives, and it encourages scholars in wealthy nations to collaborate with scholars in nations that remain underrepresented in sustainability literature. In the long-term, a placed-based, process-oriented, and fully-integrated understanding of sustainability challenges scholars of sustainability to explore new frontiers and identify communities that remain on the margins of political discourse. Their perspectives are likely to sharpen environmental debates and guide public policy toward resolutions to critical environmental and economic dilemmas. The debate that has surrounded the meaning and proper application of sustainability since its political coming-of-age is likely to continue for years into the future as unforeseen challenges emerge from places and voices that the conversation welcomes anew. We look forward to this tortuous and perhaps surprising endeavor.

Acknowledgments: This material is based upon work supported by the National Science Foundation under Grant Number 1231382. Any opinions, findings, and conclusions or recommendations expressed in this material are those of the author(s) and do not necessarily reflect the views of the National Science Foundation. The authors would like to thank members of the Integrated Network for Social Sustainability for their early contributions to the ideas in this article, and three anonymous reviewers for their constructive feedback.

Author Contributions: This paper was originally outlined in a conference presentation by Boyer to which Peterson and Arora contributed. All authors contributed to elements to different sections. Arora contributed specific examples from business and economics disciplines. Boyer contributed specific literature from urban planning and geography. Peterson contributed specific literature from anthropology. Caldwell contributed primarily to Section 4.5 of the paper, but edited other sections as well.

Conflicts of Interest: The authors declare no conflict of interest. 


\section{References}

1. Kidd, C. The evolution of sustainability. J. Agric. Environ. Ethics 1992, 5, 1-26. [CrossRef]

2. Robinson, J. Squaring the circle? Some thoughts on the idea of sustainable development. Ecol. Econ. 2004, 48, 369-384. [CrossRef]

3. Atkinson, G.; Dietz, S.; Neumayer, E.; Agarwala, M. Handbook of Sustainable Development: Second Edition; Edward Elgar Publishing: Cheltenham, UK, 2014.

4. Boström, M. SSPP: A missing pillar? Challenges in theorizing and practicing social sustainability: Introduction to the special issue. Sustain. Sci. Pract. Policy 2012, 8. Available online: http:/ / search.proquest. com/openview /a6ee08a077db2455766c0d8cc8556cb9/1?pq-origsite=gscholar (accessed on 10 April 2015).

5. Murphy, K. The social pillar of sustainable development: A literature review and framework for policy analysis. Sustain. Sci. Pract. Policy 2012, 8. Available online: http://search.proquest.com/openview/ 22134d156f502958f35a9a7450f95814/1?pq-origsite=gscholar (accessed on 10 April 2015).

6. Dempsey, N.; Bramley, G.; Power, S.; Brown, C. The social dimension of sustainable development: Defining urban social sustainability. Sustain. Dev. 2009, 19, 289-300. [CrossRef]

7. Boschmann, E.E.; Kwan, M.-P. Toward Socially Sustainable Urban Transportation: Progress and Potentials. Int. J. Sustain. Transp. 2008, 2, 138-157. [CrossRef]

8. Lenzen, M. Systems for Social Sustainability: Global Connectedness and the Tuvalu Test. Cybern. Hum. Knowing 2007, 14, 87-105.

9. Vallance, S.; Perkins, H.C.; Dixon, J.E. What is social sustainability? A clarification of concepts. Geoforum 2011, 42, 342-348. [CrossRef]

10. Rittel, H.W.J.; Webber, M.M. Dilemmas in a general theory of planning. Policy Sci. 1973, 4, 155-169. [CrossRef]

11. Agyeman, J.; Bullard, R.D.; Evans, B. Exploring the Nexus: Bringing Together Sustainability, Environmental Justice and Equity. Space Polity 2002, 6, 77-90. [CrossRef]

12. Cuthill, M. Strengthening the "social" in sustainable development: Developing a conceptual framework for social sustainability in a rapid urban growth region in Australia. Sustain. Dev. 2010, 18, 362-373. [CrossRef]

13. Swyngedouw, E. Impossible "Sustainability" and the Postpolitical Condition. In The Sustainable Development Paradox: Urban Political Economy in the United States and Europe; Krueger, R., Gibbs, D., Eds.; Guilford Press: New York, NY, USA, 2007; pp. 13-40.

14. Mauss, M. The Gift: Forms and Functions of Exchange in Primitive Societies; Cohen and West: London, UK, 1954.

15. West, P. Conservation Is Our Government Now: The Politics of Ecology in Papua New Guinea; Duke University Press: Durham, NC, USA, 2006.

16. Luke, T.W. On Environmentality: Geo-Power and Eco-Knowledge in the Discourses of Contemporary Environmentalism. Cult. Crit. 1995, 31, 57-81. [CrossRef]

17. Charmaz, K. Constructing Grounded Theory: A Practical Guide through Qualitative Analysis; Sage Publications: Thousand Oaks, CA, USA, 2006.

18. Littig, B.; Griessler, E. Social sustainability: A catchword between political pragmatism and social theory. Int. J. Sustain. Dev. 2005, 8, 65-79. [CrossRef]

19. Bramley, G.; Power, S. Urban form and social sustainability: The role of density and housing type. Environ. Plan. B Plan. Des. 2009, 36, 30-48. [CrossRef]

20. Saha, D.; Paterson, R.G. Local Government Efforts to Promote the "Three Es" of Sustainable Development: Survey in Medium to Large Cities in the United States. J. Plan. Educ. Res. 2008, 28, 21-37. [CrossRef]

21. Wackernagel, M.; Rees, W.E. Our Écological Footprint: Reducing Human Impact on the Earth; New Society Publishers: Gabriola Island, BC, Canada, 1996.

22. Orr, D.W. Two Meanings of Sustainability (1988). In Hope is an Imperative; Island Press/Center for Resource Economics: Washington, DC, USA, 2011; pp. 93-111.

23. Windle, R. The Poetry of Business Life: An Anthology; Berrett-Koehler Publishers: Oakland, CA, USA, 1994.

24. Cho, C.H.; Laine, M.; Roberts, R.W.; Rodrigue, M. Organized hypocrisy, organizational façades, and sustainability reporting. Account. Organ. Soc. 2015, 40, 78-94. [CrossRef]

25. Campbell, S. Green Cities, Growing Cities, Just Cities?: Urban Planning and the Contradictions of Sustainable Development. J. Am. Plann. Assoc. 1996, 62, 296-312. [CrossRef]

26. Amekudzi, A.A.; Khisty, J.C.; Khayesi, M. Using the sustainability footprint model to assess development impacts of transportation systems. Transp. Res. Part Policy Pract. 2009, 43, 339-348. [CrossRef] 
27. Amekudzi, A.A.; Khayesi, M.; Khisty, J.C. Sustainable development footprint: A framework for assessing sustainable development risks and opportunities in time and space. Int. J. Sustain. Dev. 2015, 18, 9-40. [CrossRef]

28. Milne, M.J.; Gray, R. W(h)ither Ecology? The Triple Bottom Line, the Global Reporting Initiative, and Corporate Sustainability Reporting. J. Bus. Ethics 2012, 118, 13-29. [CrossRef]

29. Arora, P.; Peterson, N.D. Managing the Triple Bottom Line for Sustainability: A Case Study of Argentine Agribusinesses. Sustain. Sci. Pract. Policy 2016, 12. Available online: https://sspp.proquest.com/managingthe-triple-bottom-line-for-sustainability-a-case-study-of-argentine-agribusinesses-dd4333c59d8f\#.7qrh6jw5p (accessed on 10 July 2016).

30. Peterson, N.D. Choices, Options, and Constraints: Decision Making and Decision Spaces in Natural Resource Management. Hum. Organ. 2010, 69, 54-64. [CrossRef]

31. Peterson, N.D. Excluding to include: (Non)participation in Mexican natural resource management. Agric. Hum. Values 2011, 28, 99-107. [CrossRef]

32. Sridhar, K. The Relationship between the Adoption of Triple Bottom Line and Enhanced Corporate Reputation and Legitimacy. Corp. Reput. Rev. 2012, 15, 69-87. [CrossRef]

33. Putnam, R.D.; Leonardi, R.; Nanetti, R.Y. Making Democracy Work: Civic Traditions in Modern Italy; Princeton University Press: Princeton, NJ, USA, 1993.

34. Boyer, R. Achieiving one-planet living through transitions in social practice: A case study of Dancing Rabbit Ecovillage. Sustain. Sci. Pract. Policy 2016, 12. Available online: https://sspp.proquest.com/achieving-oneplanet-living-through-transitions-in-social-practice-a-case-study-of-dancing-rabbit-ab7ffb2df28c\#.srk3u4ibb (accessed on 10 July 2016).

35. Lansing, J.S. Balinese "Water Temples” and the Management of Irrigation. Am. Anthropol. 1987, 89, 326-341. [CrossRef]

36. Anderson, E. Streetwise: Race, Class, and Change in an Urban Community; University of Chicago Press: Chicago, IL, USA, 1992.

37. Klinenberg, E. Heat Wave: A Social Autopsy of Disaster in Chicago; University of Chicago Press: Chicago, IL, USA, 2003.

38. Ostrom, E. Governing the Commons; Cambridge University Press: Cambridge, UK, 2015.

39. Arora, P.; Bert, F.; Podesta, G.; Krantz, D.H. Ownership effect in the wild: Influence of land ownership on agribusiness goals and decisions in the Argentine Pampas. J. Behav. Exp. Econ. 2015, 58, 162-170. [CrossRef]

40. Geels, F.W. The dynamics of transitions in socio-technical systems: A multi-level analysis of the transition pathway from horse-drawn carriages to automobiles (1860-1930). Technol. Anal. Strateg. Manag. 2005, 17, 445-476. [CrossRef]

41. Kemp, R.; Schot, J.; Hoogma, R. Regime shifts to sustainability through processes of niche formation: The approach of strategic niche management. Technol. Anal. Strateg. Manag. 1998, 10, 175-198. [CrossRef]

42. Rip, A. A Quasi-Evolutionary Model of Technological Development and a Cognitive Approach to Technology Policy. Riv. Studi Epistemol. E Soc. Sulla Sci. E Technol. 1992, 2, 69-102.

43. Rip, A.; Kemp, R. Technological Change. In Human Choice and Climate Change; Rayner, S., Malone, E.L., Eds.; Battelle Press: Columbus, OH, USA, 1998; pp. 327-399.

44. Geels, F.W. Technological transitions as evolutionary reconfiguration processes: A multi-level perspective and a case-study. Res. Policy 2002, 31, 1257-1274. [CrossRef]

45. Seyfang, G.; Smith, A. Grassroots innovations for sustainable development: Towards a new research and policy agenda. Environ. Politics 2007, 16, 584-603. [CrossRef]

46. Boyer, R. Grassroots innovation for urban sustainability: Comparing the diffusion pathways of three ecovillage projects. Environ. Plan. A 2015, 47, 320-337. [CrossRef]

47. Smith, A. Niche-based approaches to sustainable development: Radical activists versus strategic managers. In Reflexive Governance for Sustainable Development; Voss, J.-P., Bauknecht, D., Kemp, R., Eds.; Edward Elgar: Cheltenham, UK, 2006.

48. Hardisty, D.J.; Johnson, E.J.; Weber, E.U. A Dirty Word or a Dirty World? Attribute Framing, Political Affiliation, and Query Theory. Psychol. Sci. 2010, 21, 86-92. [CrossRef] [PubMed]

49. Pichert, D.; Katsikopoulos, K.V. Green defaults: Information presentation and pro-environmental behaviour. J. Environ. Psychol. 2008, 28, 63-73. [CrossRef] 
50. Arora, P.; Peterson, N.D.; Krantz, D.H.; Hardisty, D.J.; Reddy, K.S. To cooperate or not to cooperate: Using new methodologies and frameworks to understand how affiliation influences cooperation in the present and future. J. Econ. Psychol. 2012, 33, 842-853. [CrossRef]

51. Rajagopal, D.; Attari, S. Enabling energy conservation through effective decision aids. J. Sustain. Educ. 2015, 8. Available online: http://www.jsedimensions.org/wordpress/content/enabling-energy-conservationthrough-effective-decision-aids_2015_01/(accessed on 10 July 2016).

52. Goldstein, N.J.; Cialdini, R.B.; Griskevicius, V. A Room with a Viewpoint: Using Social Norms to Motivate Environmental Conservation in Hotels. J. Consum. Res. 2008, 35, 472-482. [CrossRef]

53. Abel, T.D.; White, J. Gentrified sustainability: Inequitable development and Seattle's skewed riskscape. Interdiscip. Environ. Rev. 2015, 16, 124-157. [CrossRef]

54. Abel, T.D. Skewed Riskscapes and Environmental Injustice: A Case Study of Metropolitan St. Louis. Environ. Manag. 2008, 42, 232-248. [CrossRef] [PubMed]

55. Bullard, R.D.; Johnson, G.S.; Torres, A.O. Highway Robbery: Transportation Racism E New Routes to Equity; South End Press: Brooklyn, NY, USA, 2004.

56. Mann, E. Los Angeles Bus Riders Derail the MTA. In Highway Robbery: Transportation Racism \& New Routes to Equity; Bullard, R.D., Johnson, G.S., Torres, A.O., Eds.; South End Press: Brooklyn, NY, USA, 2004; pp. $33-47$.

57. Maantay, J. Zoning, equity, and public health. Am. J. Public Health 2001, 91, 1033-1041. [PubMed]

58. Williams, B. A River Runs through US. Am. Anthropol. 2001, 103, 409-431. [CrossRef]

59. Maldonado, J.K.; Shearer, C.; Bronen, R.; Peterson, K.; Lazrus, H. The impact of climate change on tribal communities in the US: Displacement, relocation, and human rights. Clim. Chang. 2013, 120, 601-614. [CrossRef]

60. Marino, E. The long history of environmental migration: Assessing vulnerability construction and obstacles to successful relocation in Shishmaref, Alaska. Glob. Environ. Chang. 2012, 22, 374-381. [CrossRef]

61. Shove, E.; Pantzar, M.; Watson, M. The Dynamics of Social Practice: Everyday Life and How It Changes; SAGE Publications: Thousand Oaks, CA, USA, 2012.

62. Shove, E.; Walker, G. What Is Energy For? Social Practice and Energy Demand. Theory Cult. Soc. 2014, 31, 41-58. [CrossRef]

63. Latour, B. We Have Never Been Modern; Harvard University Press: Cambridge, MA, USA, 2012.

64. Warren, K. Ecofeminist Philosophy: A Western Perspective on What It Is and Why It Matters; Rowman \& Littlefield: Lanham, MD, USA, 2000.

65. Richardson, J. Accounting for sustainability: Measuring quantities or enhancing qualities? In The Triple Bottom Line: Does It All Add Up; Henriques, A., Richardson, J., Eds.; Earthscan: Abingdon-on-Thames, UK, 2013.

66. Esteva, G. Commoning in the new society. Community Dev. J. 2014, 49, i144-i159. [CrossRef]

67. Esteva, G.; Prakash, M.S. Grassroots Post-Modernism: Remaking the Soil of Cultures; Palgrave Macmillan: Basingstoke, UK, 1998.

68. Krueger, R.; Agyeman, J. Sustainability schizophrenia or "actually existing sustainabilities?" toward a broader understanding of the politics and promise of local sustainability in the US. Geoforum 2005, 36, 410-417. [CrossRef]

69. Hurley, P.T.; Walker, P.A. Whose vision? Conspiracy theory and land-use planning in Nevada County, California. Environ. Plan. A 2004, 36, 1529-1547. [CrossRef]

70. Angus-Leppan, T.; Benn, S.; Young, L. A sensemaking approach to trade-offs and synergies between human and ecological elements of corporate sustainability. Bus. Strategy Environ. 2010, 19, 230-244. [CrossRef]

71. Raymond, C.M.; Fazey, I.; Reed, M.S.; Stringer, L.C.; Robinson, G.M.; Evely, A.C. Integrating local and scientific knowledge for environmental management. J. Environ. Manag. 2010, 91, 1766-1777. [CrossRef] [PubMed]

72. Haenn, N. The Power of Environmental Knowledge: Ethnoecology and Environmental Conflicts in Mexican Conservation. Hum. Ecol. 1999, 27, 477-491. [CrossRef]

73. Nazarea, V.D. Local Knowledge and Memory in Biodiversity Conservation. Annu. Rev. Anthropol. 2006, 35, 317-335. [CrossRef]

74. Corburn, J. Bringing Local Knowledge into Environmental Decision Making Improving Urban Planning for Communities at Risk. J. Plan. Educ. Res. 2003, 22, 420-433. [CrossRef] 
75. West, P. Translation, Value, and Space: Theorizing an Ethnographic and Engaged Environmental Anthropology. Am. Anthropol. 2005, 107, 632-642. [CrossRef]

76. Rice, J.L.; Burke, B.J.; Heynen, N. Knowing Climate Change, Embodying Climate Praxis: Experiential Knowledge in Southern Appalachia. Ann. Assoc. Am. Geogr. 2015, 105, 253-262. [CrossRef]

77. Bryson, J.M.; Quick, K.S.; Slotterback, C.S.; Crosby, B.C. Designing Public Participation Processes. Public Adm. Rev. 2013, 73, 23-34. [CrossRef]

78. Cooke, B.; Kothari, U. Participation: The New Tyranny?; Zed Books: London, UK, 2001.

79. Hickey, S.; Mohan, G. Participation-From Tyranny to Transformation?: Exploring New Approaches to Participation in Development; Zed Books: London, UK, 2004.

80. Peterson, N.D.; Broad, K.; Orlove, B.; Roncoli, C.; Taddei, R.; Velez, M.-A. Participatory processes and climate forecast use: Socio-cultural context, discussion, and consensus. Clim. Dev. 2010, 2, 14-29. [CrossRef]

81. Lowry, K.; Adler, P.; Milner, N. Participating the Public: Group Process, Politics, and Planning. J. Plan. Educ. Res. 1997, 16, 177-187. [CrossRef]

82. Bryson, J.M. What to do when Stakeholders matter. Public Manag. Rev. 2004, 6, 21-53. [CrossRef]

83. Quick, K.S.; Feldman, M.S. Distinguishing Participation and Inclusion. J. Plan. Educ. Res. 2011, 31, $272-290$. [CrossRef]

84. McDowell, T.; Hernández, P. Decolonizing Academia: Intersectionality, Participation, and Accountability in Family Therapy and Counseling. J. Fem. Fam. Ther. 2010, 22, 93-111. [CrossRef]

85. Escobar, A. Territories of Difference: Place, Movements, Life, Redes; Duke University Press: London, UK, 2008.

86. Sandercock, L. Towards Cosmopolis: Planning for Multicultural Cities; John Wiley: Hoboken, NJ, USA, 1998.

87. Peterson, N.D. Introduction to the special issue on social sustainability: Integration, context, and governance. Sustain. Sci. Pract. Policy 2016, 12. Available online: https://sspp.proquest.com/introduction-to-the-specialissue-on-social-sustainability-integration-context-and-governance-dc31ee5cf89e\#.12mihsrbk (accessed on 10 July 2016).

88. Wolsko, C.; Marino, E.; Doherty, T.; Fisher, S.; Goodwin, B.; Green, A.; Reese, R.; Wirth, A. Systems of Access: A Multidisciplinary Strategy for Assessing the Social Dimensions of Sustainability. Sustain. Sci. Pract. Policy 2016, 12. Available online: https:/ /sspp.proquest.com/classification-of-social-ecological-systems-of-accessa-multidisciplinary-strategy-for-assessing-f9d79ea2b5a4\#.axjoiq5ez (accessed on 10 July 2016).

89. Shiroyama, H.; Yarime, M.; Matsuo, M.; Schroeder, H.; Scholz, R.; Ulrich, A.E. Governance for sustainability: Knowledge integration and multi-actor dimensions in risk management. Sustain. Sci. 2012, 7, 45-55. [CrossRef]

90. Magee, L.; Scerri, A.; James, P.; Thom, J.A.; Padgham, L.; Hickmott, S.; Deng, H.; Cahill, F. Reframing social sustainability reporting: Towards an engaged approach. Environ. Dev. Sustain. 2012, 15, 225-243. [CrossRef]

91. Mutisya, E.; Yarime, M. Moving towards urban sustainability in Kenya: A framework for integration of environmental, economic, social and governance dimensions. Sustain. Sci. 2013, 9, 205-215. [CrossRef]

92. Donevska, N. Trade-offs in sustainable urban development: The case of Skopje. J. Environ. Stud. Sci. 2015, 1-8. [CrossRef]

93. Milan, B.F. How participatory planning processes for transit-oriented development contribute to social sustainability. J. Environ. Stud. Sci. 2016, 6, 520-524. [CrossRef]

94. RedWind Group. Tribal Self-Assessment Tool: Resources for Development the Economic Potential of the Indian Country. Available online: http://www.redwindgroup.com/wp-content/themes/H5/pdfs/TSAT_ Mailer.PDF (accessed on 25 August 2016).

(C) 2016 by the authors; licensee MDPI, Basel, Switzerland. This article is an open access article distributed under the terms and conditions of the Creative Commons Attribution (CC-BY) license (http://creativecommons.org/licenses/by/4.0/). 